OPEN ACCESS

Edited by:

Shabir Hussain Wani,

Sher-e-Kashmir University

of Agricultural Sciences

and Technology, India

Reviewed by:

Amjad lqbal,

Abdul Wali Khan University Mardan,

Pakistan

Veysel Turan,

Bingöl University, Turkey

*Correspondence:

Xiukang Wang

wangxiukang@yau.edu.cn

Muhammad Kamran

kamiagrarian763@gmail.com

Gonzalo A. Díaz

g.diaz@utalca.cl

Shah Fahad

shah_fahad80@yahoo.com

${ }^{\dagger}$ These authors have contributed equally to this work

Specialty section:

This article was submitted to

Plant Biotechnology,

a section of the journal

Frontiers in Plant Science

Received: 29 October 2021

Accepted: 27 December 2021

Published: 13 January 2022

Citation:

lqbal S, Wang X, Mubeen I, Kamran M, Kanwal I, Díaz GA,

Abbas A, Parveen A, Atiq MN, Alshaya H, Zin El-Abedin TK and

Fahad S (2022) Phytohormones

Trigger Drought Tolerance in Crop

Plants: Outlook and Future

Perspectives.

Front. Plant Sci. 12:799318.

doi: 10.3389/fpls.2021.799318

\section{Phytohormones Trigger Drought Tolerance in Crop Plants: Outlook and Future Perspectives}

\author{
Shehzad Iqbal'1t, Xiukang Wang ${ }^{2 *}$, Iqra Mubeen ${ }^{3 \dagger}$, Muhammad Kamran ${ }^{4 *}$, Iqra Kanwal5, \\ Gonzalo A. Díaz ${ }^{1 *}$, Aqleem Abbas ${ }^{6}$, Aasma Parveen ${ }^{7}$, Muhammad Nauman Atiq ${ }^{6}$, \\ Huda Alshaya ${ }^{8}$, Tarek K. Zin El-Abedin ${ }^{9}$ and Shah Fahad ${ }^{10,11 *}$
}

\begin{abstract}
${ }^{1}$ Faculty of Agriculture Sciences, Universidad De Talca, Talca, Chile, ${ }^{2}$ Shaanxi Key Laboratory of Chinese Jujube, College of Life Sciences, Yan'an University, Yan'an, China, ${ }^{3}$ Key Lab of Integrated Crop Disease and Pest Management of Shandong Province, College of Plant Health and Medicine, Qingdao Agricultural University, Qingdao, China, ${ }^{4}$ School of Agriculture, Food, and Wine, The University of Adelaide, Adelaide, SA, Australia, ${ }^{5}$ Department of Plant Pathology, University of Agriculture, Faisalabad, Pakistan, ${ }^{6}$ College of Plant Science and Technology, Huazhong Agricultural University, Wuhan, China, ${ }^{7}$ Department of Soil Science, Faculty of Agriculture and Environmental Sciences, The Islamia University of Bahawalpur, Bahawalpur, Pakistan, ${ }^{8}$ Cell and Molecular Biology, University of Arkansas, Fayetteville, NC, United States, ${ }_{9}^{9}$ Department of Agriculture and Biosystems Engineering, Faculty of Agriculture (El-Shatby), Alexandria University, Alexandria, Egypt, ${ }^{10}$ Hainan Key Laboratory for Sustainable Utilization of Tropical Bioresource, College of Tropical Crops, Hainan University, Haikou, China, ${ }^{11}$ Department of Agronomy, The University of Haripur, Haripur, Pakistan
\end{abstract}

In the past and present, human activities have been involved in triggering global warming, causing drought stresses that affect animals and plants. Plants are more defenseless against drought stress; and therefore, plant development and productive output are decreased. To decrease the effect of drought stress on plants, it is crucial to establish a plant feedback mechanism of resistance to drought. The drought reflex mechanisms include the physical stature physiology and biochemical, cellular, and molecular-based processes. Briefly, improving the root system, leaf structure, osmoticbalance, comparative water contents and stomatal adjustment are considered as most prominent features against drought resistance in crop plants. In addition, the signal transduction pathway and reactive clearance of oxygen are crucial mechanisms for coping with drought stress via calcium and phytohormones such as abscisic acid, salicylic acid, jasmonic acid, auxin, gibberellin, ethylene, brassinosteroids and peptide molecules. Furthermore, microorganisms, such as fungal and bacterial organisms, play a vital role in increasing resistance against drought stress in plants. The number of characteristic loci, transgenic methods and the application of exogenous substances [nitric oxide, $\left(\mathrm{C}_{28} \mathrm{H}_{48} \mathrm{O}_{6}\right)$ 24-epibrassinolide, proline, and glycine betaine] are also equally important for enhancing the drought resistance of plants. In a nutshell, the current review will mainly focus on the role of phytohormones and related mechanisms involved in drought tolerance in various crop plants.

Keywords: phytohormones, drought stress, microorganisms, tolerance mechanisms, genes

\section{INTRODUCTION}

Plants are influenced by both biotic and abiotic factors, and in response to these factors, numerous internal changes occur in plants. These biotic and abiotic factors influence plant growth and development along with productivity. Biotic factors are interactions of organisms with plants that have both positive and negative effects. Positive effects may have a beneficial influence on plant 
growth. Negative effects may include allelopathy, herbivory influence, or pathogen infection in plants (Ciura and Kruk, 2018). Plant defense systems with various chemical compounds help to resist those negative effects ( $\mathrm{Li}$ et al., 2019; Riaz et al., 2021), as described briefly in Figure 1. Plant cell walls are proteins (antimicrobial) and secondary metabolites reservoirs with a highly weighted molecular layer of polysaccharides that resist pathogen physical penetration and growth.

Notably, the innate immune defense system of plants limits pathogen expansion through PTI (pattern-triggered immunity), PRRs (pattern recognition receptors), and ETI (effector-triggered immunity). ETI forms lesions on plant surfaces that restrict the further movement of pathogens from the infection site (Nishiyama et al., 2013). These defense systems activate a league of defense responses against pathogens in plant infection sites (Teixeira et al., 2019). In response to biotic and abiotic factors, plants have growth regulatory hormones that play a crucial function (Ciura and Kruk, 2018; Ali et al., 2021a). Plant growth hormones, primarily known as phytohormones, are organic, natural and small lipophilic compounds. Phytohormones play a significant role in response to different biotic and abiotic stresses along with the coordination and regulation among most developmental and growth functions in plants (Jiang and Asami, 2018). Also, they regulate cellular processes and respond very effectively to external stimuli and changing environmental conditions, even at very low concentrations (Nowicka et al., 2018).

Phytohormones with low molecular weights are more frequently adopted defense mechanisms of plants to receive external stimuli precisely against biotic stresses (Cao et al., 2011; Parveen et al., 2020). Based on phytohormone physiological functions and chemical structures, there were only a few regulatory hormones, namely jasmonic acid (JA), salicylic acid (SA), ethylene (ET), auxins (IAA), gibberellins (GAs), abscisic acid (ABA), and cytokinins (CKs), which have been more often studied by plant biologists (Dubois et al., 2018). However, presently, brassinosteroids (BRs), jasmonic acid-based compounds, cytokinins based compounds (zeatin), salicylic acidbased compounds, strigolactones, and peptides are also being investigated as plant hormones ( $\mathrm{Hu}$ et al., 2020). Based on the chemical structures of some specific groups, phytohormones are further subdivided (Péret et al., 2013) and are responsible for the formation of roots and tropism and elongation. Seed and bud dormancy occurs by inhibiting phytohormones that resist abiotic stresses, and growth becomes active after the environment becomes favorable for growth (Liu J. et al., 2019). Various derivatives of all phytohormones are present, such as transport, activated or inactivated storage forms, degradation metabolites and, most importantly, sugar or amino acid conjugates. The biological effects of many plant growth hormones are the result of the combined induction of more than one hormone. Free hormones show similar biological activity to these derivatives; therefore, a precise concentration is required for maximum effect estimations (Zhao et al., 2019), and the estimation of the effect is shown in Figure 2. Many techniques have been used for phytohormone separation to study their effects more deeply. First, thin layer chromatography techniques (Stec et al., 2016) and high-performance liquid chromatography techniques are most commonly used for plant growth hormone separation (Floková et al., 2014). GC-MSbased methods are used to profile and study phytohormone profiles in citrus species, particularly in Citrus sinensis L., to recognize the responses to biological and environmental stresses. Specific ionic monitoring (SIM) methods were used to evaluate the description of phytohormones. Two derivation reagents, N-Methyl-N-(trimethylsilyl) trifluoroacetamide (MSTFA) and methyl chloroformate (MCF), and one extraction solvent mixture were used. This method showed recovery with a high extraction percentage and reproducibility with a low limit of quantification and detection. With this method, they detected thirteen (13) phytohormones, such as auxins, salicylic acids, gibberellin, jasmonic acid, and abscisic acid, that belong to different groups. Jasmonic acid and auxins were only present in the vegetation of plants, abscisic acid was in the leaves and roots and salicylic acid, cytokinins and gibberellins were found in all plants. Phytohormones are present at extremely low concentrations in plants, making their analysis more difficult. Salicylic acid (SA) is the most abundant phytohormone present in various tissues, mostly ranging from 59 to $70 \%$ of growth hormones. ABA phytohormone was the highest among SA groups, and GA7 was the most abundant among all GA groups and was made from GA12 in the $3 \beta$-hydroxy gibberellic acid pathway (Farrow and Facchini, 2014).

Drought being one of the abiotic stresses, is the most compelling ecological issue that significantly damages plant photosynthesis, development and growth (Rizwan et al., 2015; Fahad et al., 2017). Perennial fruit trees and crops demand well-drained soils for healthy growth and development and to obtain the maximum level of productivity. Even for a short time, poor drainage can markedly affect the productivity of perennial fruit trees for extended durations (Fahad et al., 2017; Fuller and Stevens, 2019). Moreover, drought stress causes an imbalance in carbon metabolism, which is the primary source of carbohydrates, leading to partial stomatal closure at carboxylation sites with less carbon dioxide availability ( $\mathrm{Hu}$ et al., 2019). In addition, drought stress also causes the shoot respiration level to increase to sustain metabolic activity. Then, a decrease in the carbohydrate reserves occurs in the storage organs of citrus plants (Fahad et al., 2017).

Moderate drought stress leads to increased leaf soluble carbohydrate concentrations, a reduction in starch concentrations and a low photosynthesis rate in leaves. Plants may use stored carbohydrates because changes in carbon availability are observed under low photosynthesis rates. To meet the plant metabolic demand, these plants stored reservoirs to overcome stressful drought conditions (Fahad et al., 2017; Liu Y. N. et al., 2019). However, severe drought stress reduces starch and soluble fraction levels (Rizwan et al., 2015; Fahad et al., 2017). Plants exposed to saline environments experience a decline in plant growth because of the effect of specific ions on metabolism and antagonistic environmental connections. Various technologies have been used to exploit citrus plant growth under drought stress. Attempts are being made through conventional breeding methods to improve plants tolerance to 


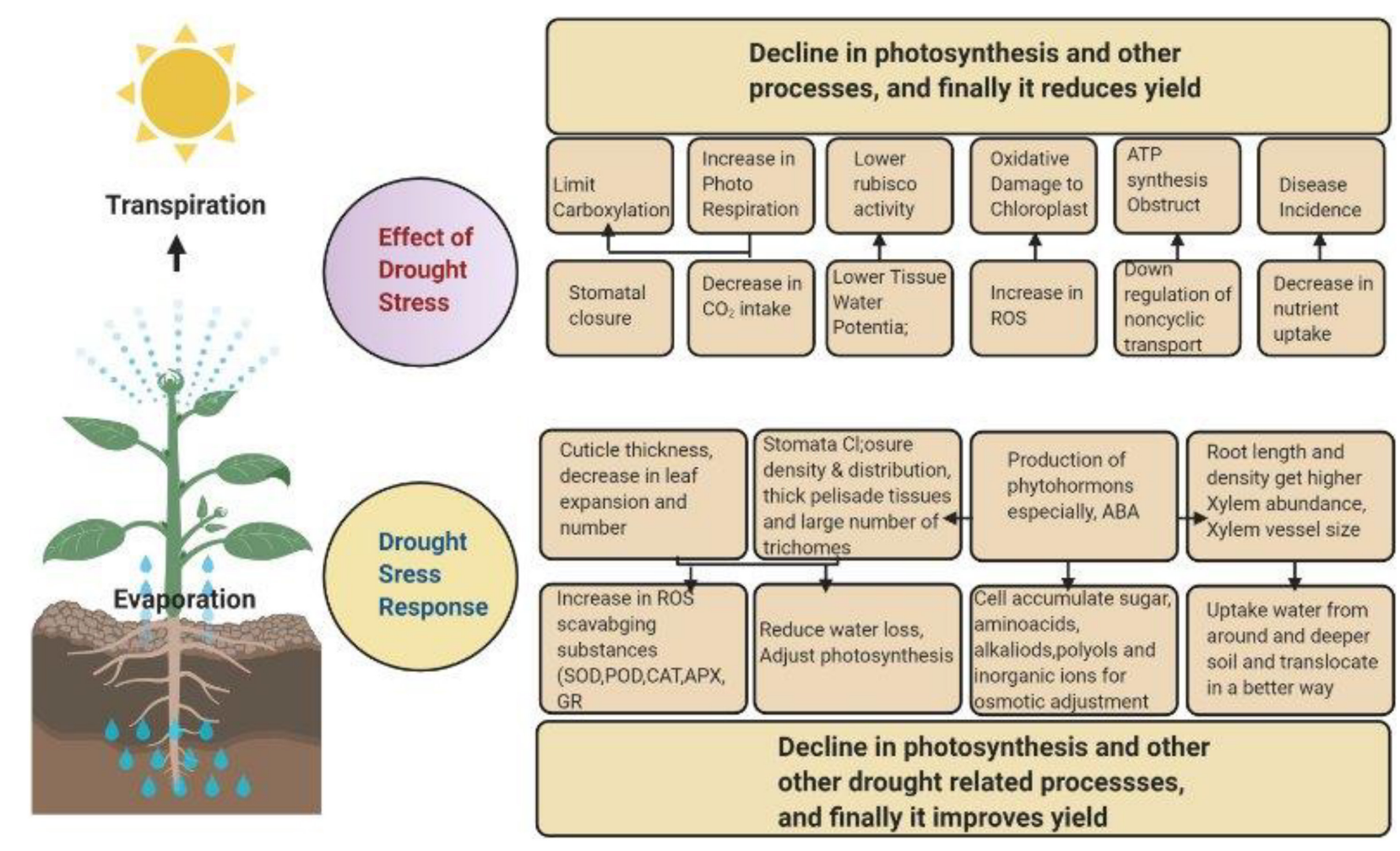

FIGURE 1 | Crop response, from physiological and morphological perspectives to drought stress. Drought stress affects the normal functioning of plants by lowering the rate of photosynthesis. To overcome this issue, plants increase the production of hormones and photosynthesis-related components as a defense mechanism.

drought stress, and these methods are laborious and based on the prevailing genetic changeability. Recently various drought resistance genes were overexpressed in plants, and plants become tolerant to drought stress. In most cases, a higher yield was recorded in the transgenic plants than the wild type plants. Some of the drought-tolerant plants have been listed in Table 1.

In response to abiotic stresses, i.e., drought and salinity, plants have developed various physiology, phenology, morphology, and biochemical-based mechanisms to sustain their cellular osmotic potential (Fahad et al., 2015, 2017, 2018, 2020, 2021a,b,c,d,e,f; Kamran et al., 2019; Ali et al., 2021a). Various studies on these mechanisms are ongoing due to the involvement of multiple phytohormones acting as sole mediators for avoidance, tolerance, and the adverse effect of water stress. Plant hormones vitally regulate the development and growth of plants along with drought stress reflexes throughout the lifespans of plants (Sah et al., 2016; Ullah et al., 2017). In response to drought stress, plants produce phytohormones that transduce the pathway to regulate its impact (Fahad et al., 2017; Hamayun et al., 2018). Also, phytohormones activate different developmental and physiological processes, such as negative phototropism in roots, osmotic balance, and closing stomata (Lim et al., 2015; Zahid et al., 2016).

Exogenous applications of plant growth regulators are also employed to overcome these stressed conditions (Kamran et al., 2021). As mentioned, phytohormones were applied to improve drought tolerance in plants (see Table 2) and increase growth, development, and productivity. Phytohormones play important roles in modifying the plant reflex to strains at very low concentrations, and their chemical messenger properties are produced in one part of the plant and transferred to entire parts of plants. Phytohormones are natural products synthesized chemically as plant growth regulators (Sah et al., 2016).

\section{PLANT HORMONES IMPROVE DROUGHT RESISTANCE IN PLANTS}

\section{Auxins}

Auxin is an important phytohormone. Auxins are involved in cell division, cell elongation and the differentiation of cellular tissues, embryogenesis, root formation, apical dominance, phyllotaxis, and tropic responses. Auxin genes are important biotechnological targets for modifying plant size and shape and improving plant yield. Therefore, they play a vital role in cell and growth development (Asgher et al., 2015). Auxins also play a dynamic role in mediating and improving plant tolerance to noninfectious stresses, such as deficiency conditions, as represented by many research reports (Kazan, 2013). Indole-3-acetic acid was one of the first hormones recognized in this group and is most commonly found among the auxins (Hamayun et al., 2021c). Indole 3-acetic acid is produced from tryptophan and is chemically similar to it. Alterations in gene expression patterns 


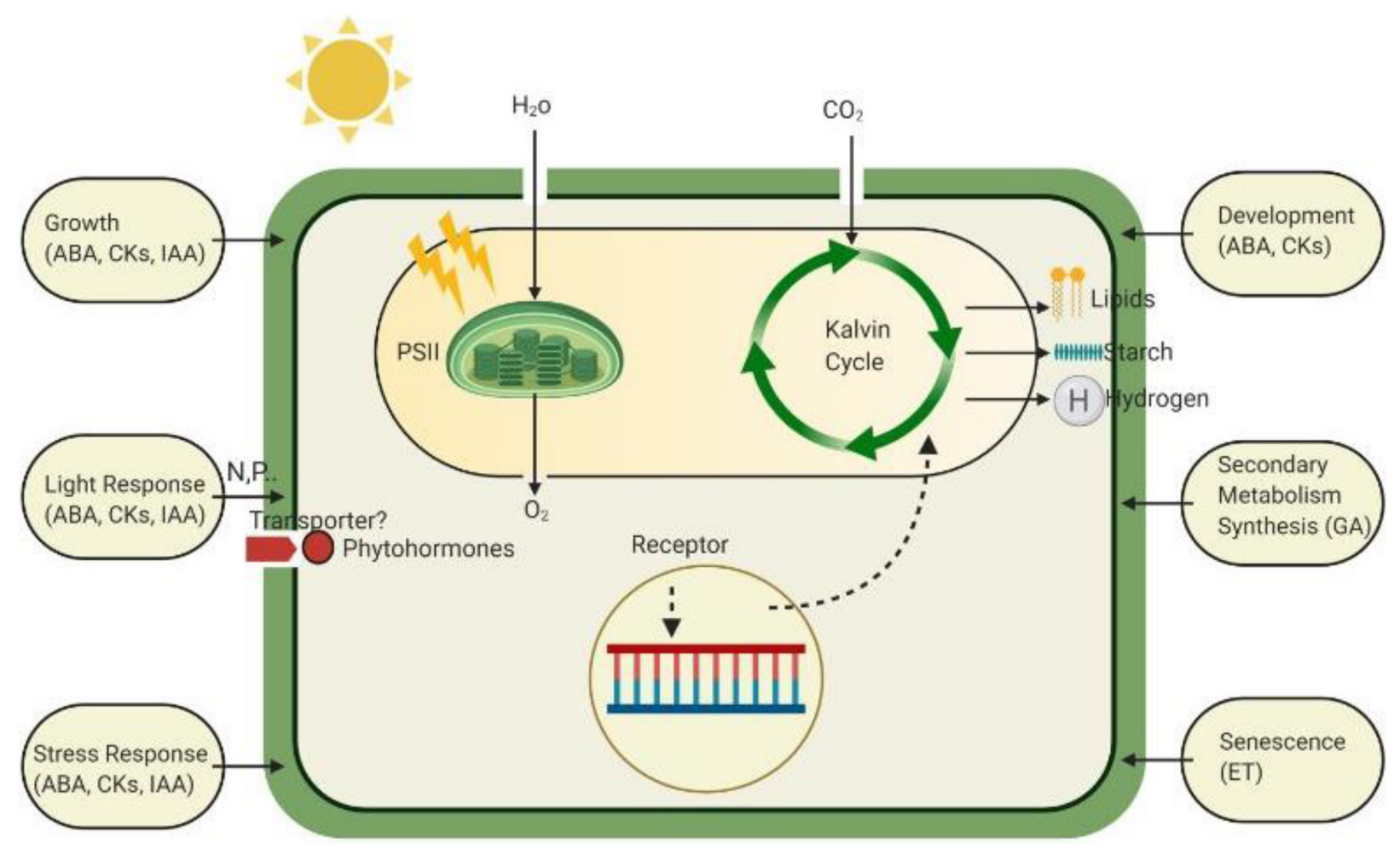

FIGURE 2 | The role of various phytohormones in plants to defend against different stressed conditions by increasing or decreasing their levels. Unstable levels of these hormones work within the defense mechanism of plants to ensure healthy normal growth.

were used to control auxin-mediated growth and development. When plants are exposed to drought and other stress conditions, varied modulations in the synthesis, metabolism, transport, and activity of auxins take place, as depicted in various reports (Ljung, 2013). A decline in the IAA level under stress conditions can increase the ABA level in plants to induce growth modulation by auxins. Jung et al. (2015) mentioned that among auxin-coding genes recognized in rice plants, some genes were activated by drought stress. Previous studies also reported the overexpression of YUC6 in poplar and potato, resulting in auxin-enhanced drought tolerance and phenotypes (Ke et al., 2015). Auxins also promote root branching and have a potential role in drought tolerance mechanisms in tobacco seedlings (Verma et al., 2016; Wang et al., 2018). Auxin response factors (ARFs) bind directly to the promoters of auxin-responsive genes, allowing them to be activated or repressed transcriptionally and enhance stress tolerance in tomatoes (Bouzroud et al., 2018). In addition, these ARFs regulate genes (WRKY108715, MYB14, DREB4, and bZIP 107) involved in drought stress response and enhanced tolerance in clovers (Zhang et al., 2020).

The role of auxin in drought stress has been explored via TLD1/OsGH3.13 which encodes indole-3-acetic acid (IAA)amido synthase; it then enhanced the expression of late embryogenesis abundant (LEA) genes, which then increase the resistance in plants against drought stress. In addition, genes Aux/IAA genes were identified in rice and most of these genes were expressed under drought stress. In a study, YUC6 was overexpressed in potato and poplar which showed auxin-overproduction phenotypes and enhanced drought tolerance (Colebrook et al., 2014b). Auxin also enhanced drought resistance by interacting with other phytohormones. For example, auxin regulates various members of the ACS (1aminocyclopropane-1-carboxylate synthase) gene family, which is a rate-limiting enzyme in ethylene biosynthesis. This interaction enhances resistance in plants against drought stress (Colebrook et al., 2014b).

\section{Cytokinin}

Cytokinins were discovered in 1950, and they are the most important phytohormones that stimulate cell division and induce variations. The first natural cytokinin was trans-zeatin, which was isolated from maize (Miller, 1961). These compounds are adenine byproducts derived from isoprene or an aromatic side chain at the N6 position of purine. Folke Skoog and his assistants isolated kinetin (the cytokinesis-promoting factor) from autoclaved herring sperm DNA (Miller, 1961). These hormones are essential for the growth of plant regulation and acclimation to drought stress (Li et al., 2016). Cytokinins have both negative and positive impacts on drought stress (Ha et al., 2012; Li et al., 2016).

The enhancement or reduction of the cytokinin level depends on the period and severity of the drought stress (Zwack and Rashotte, 2015). The beneficial aspects are enhanced intolerance against drought stress. CKs are also 
TABLE 1 | Transgenic crops under drought stress experienced altered yields through the phytohormone signaling pathway.

\begin{tabular}{|c|c|c|c|c|c|c|}
\hline Gene(s) & Expressing plant & $\begin{array}{l}\text { Signaling } \\
\text { pathway }\end{array}$ & Stress type & Environmental condition(s) & $\begin{array}{l}\text { Effect on yield } \\
\text { (increase (\%) }\end{array}$ & References \\
\hline AtYUCCA6 & Solanum tuberosum & Auxin & Drought & Greenhouse & Data not shown & Im Kim et al., 2013 \\
\hline LOS5ABA3 & Glycine max & ABA & Drought & Growth chamber and field & $21 \%$ & Li et al., 2013 \\
\hline AtEDT1/HDG11 & Oryza sativa & ABA & Drought & Greenhouse and field & $16 \%$ & Yu et al., 2013 \\
\hline AtGAMT1 & Solanum lycopersicum & GAs & Drought & Greenhouse & Data not shown & Nir et al., 2014 \\
\hline AtEDT1/HDG11 & Gossipium hirsutum & ABA & Drought and salinity & Laboratory, greenhouse and field & $43 \%$ & Yu et al., 2016 \\
\hline GhABF2 & Gossipium hirsutum & ABA & Drought and salinity & Laboratory, greenhouse, and field & $46 \%$ & Liang et al., 2016 \\
\hline JIOsPR10 & Oryza sativa & $J A$ & $\begin{array}{c}\text { Drought, salt and } \\
\text { Magnaporthe oryzae }\end{array}$ & Greenhouse & No change & Wu et al., 2016 \\
\hline GA2Ox & Oryza sativa & GAs & Drought and disease & Greenhouse and field & $10-30 \%$ & Lo et al., 2017 \\
\hline OsERF109 & Oryza sativa & JA and $A B A$ & Drought & Greenhouse & $30-45 \%$ & Yu et al., 2016 \\
\hline
\end{tabular}

TABLE 2 | Phytohormones functions to prevent plants from drought stress.

\begin{tabular}{|c|c|c|}
\hline Functions & Hormones & References \\
\hline Involved in cell division, cell elongation, apical dominance, phyllotaxis and tropic responses & Auxin & Im Kim et al., 2013 \\
\hline Root branching & Auxin & Im Kim et al., 2013 \\
\hline Growth of plant parts and the flowering stage & Cytokinins & Liang et al., 2016 \\
\hline Development of female gametes and embryos & Cytokinins & Wu et al., 2016 \\
\hline Photomorphogenesis and leaf senescence & Cytokinins & Ha et al., 2012 \\
\hline Cell elongation and increasing the cell division & Gibberellins & Colebrook et al., $2014 \mathrm{a}$ \\
\hline Enhance the vegetative and reproductive stages of plants & Gibberellins & Li et al., $2012 \mathrm{a}$ \\
\hline Stomatal closure, gene upregulation and compatible osmolyte synthesis & Abscisic acid (ABA) & Shi et al., 2018 \\
\hline Photosynthetic activity, stomatal regulation, root growth, and germination & Abscisic acid (ABA) & Seo and Koshiba, 2011 \\
\hline Defense responses & Salicylic acid (SA) & Miura et al., 2013 \\
\hline Progressive responses against elevated temperature stress & Salicylic acid (SA) & Munne-Bosch and Penuelas, 2003 \\
\hline Stomatal closure & Salicylic acid (SA) & Dempsey et al., 2011a \\
\hline Drought tolerance by lessening transpiration, squeezing the aperture of the stomata, and thinning the cuticle & Ethylene & Zandalinas et al., 2016 \\
\hline Appraisal of growth, drought tolerance, and yields & Brassinosteroids & Li et al., 2012b \\
\hline Stomatal closing & Jasmonic Acid (JA) & De Ollas et al., 2013 \\
\hline Increase the antioxidant activity of plants under drought & Jasmonic Acid (JA) & Dong and Hwang, 2014 \\
\hline Root growth, pollen tube growth, stomatal development & Peptides & Shi et al., 2018 \\
\hline
\end{tabular}

reported to stimulate transgene expression in transgenic plants, i.e., isopentenyl transferase gene expression. The transgenic plants indicated significant drought tolerance through delayed senescence by restricting drought-induced leaf senescence. The negative effects of $\mathrm{CK}$ accumulation on drought tolerance have also been reported along with the positive effects of CK accumulation. CK oxidase/dehydrogenase (CKX) catalyzes CK and is involved in the overexpression and breakdown of CKX in Arabidopsis, which results in a decrease in endogenous CK contents (Werner et al., 2010; Hamayun et al., 2021b). Therefore, CKX1, CKX2, CKX3, and CKX4 were overexpressed independently in Arabidopsis, resulting in transgenic lines with reduced CK levels and subsequently greater drought tolerance.

Cytokinins are helpful in plant tissue culture techniques and support the thoughtful study of plant biological processes, such as the growth of plant parts and the flowering stage. These compounds are responsible for stimulating different processes during the growth and development of female gametes and embryos of a plant. Notably, cytokinins also participate in seed germination, vascular development, photomorphogenesis, shoot apical meristem development, floral development, and leaf senescence. It also helps plants to induce adaptive responses to drought and adverse ecological conditions (Mao et al., 2020). Moreover, different hormones and macronutrients control the transcription of cytokinin biosynthetic genes. In Arabidopsis, cytokinins stimulate cell division by antagonizing auxin. Auxin promotes the expression of AtIPT5 and AtIPT7, whereas cytokinins suppress the expression of AtIPT1, AtIPT3, AtIPT5, and AtIPT7 in the shoot meristem (Ismail H. M. et al., 2020).

All the genes related to cytokinin in Arabidopsis were overexpressed individually, and transgenic lines of Arabidopsis with decreased levels of cytokinin gradually improved tolerance to drought conditions (Nishiyama et al., 2011). The current need is to elucidate the signaling and role of cytokinins under drought conditions.

\section{Gibberellins}

Gibberellins are tetracyclic diterpenoids of carboxylic acids. The primary purpose of GAs in plants is as growth hormones and 
to provide resistance against drought stress and other abiotic stresses. GAs continues their functions in plants throughout the plant life cycle. The primary purpose of gibberellins is to enhance the development of plant tissues by cell elongation and increasing the cell division process enhances the immature and adult stages of plant growth. It also helps to enhance the vegetative and reproductive stages of plants (Colebrook et al., 2014b; Kang et al., 2019).

SIDREB (drought-responsive element-binding protein) increases drought tolerance in tomatoes by decreasing the expression of gibberellin biosynthesis genes (Colebrook et al., 2014a). Drought tolerance is said to be enhanced if the GA level is reduced in plants. Transgenic tomatoes are produced by the overexpression of the AtGAMT1 (Arabidopsis thaliana GA Methyl Transferase-1) gene. AtGAMT1 encodes an enzyme that causes a breakdown in the methylation of active GA to make inactive GA methyl esters. The transgenic tomato indicated a reduction in gibberellins by enhanced drought tolerance. An increased water level in leaves was observed in transgenic tomatoes under drought stress because of transpiration in plants (Nir et al., 2014). The ectopic expression of GA2ox (GA 2-oxidase) increased drought tolerance. This protein also helps to enhance resistance in rice plants (Lo et al., 2017). The DELLAs proteins are the primary stimulators of GA responses in drought conditions faced by plants. The functions of this group of nuclear regulators are to suppress gibberellin stimulation in plants. Gibberellins binding to the receptor GID1 (GA in-sensitive dwarf 1) lead to the degradation of DELLAs by the $26 \mathrm{~S}$ proteasome and the stimulation of gibberellin responses (Li et al., 2012c).

Drought tolerance in plants is appreciably enhanced by gibberellins, as reported in many studies (Li et al., 2012a; Colebrook et al., 2014a). Tomatoes make the transgene by overexpressing the gene (methyltransferase 1). GAMT1 encodes an enzyme catalyzing active gibberellin methylation to form inactivated GA methyltransferase in Arabidopsis spp. The resulting tomato plant expressed a typical GA-deficient phenotype, which showed drought tolerance. A high-water content was prominent in transgene tomato plants because of decreased transpiration (Ullah et al., 2018). By contrast, applying hormones resulted in the reappearance of normal growth, and plants became prone to drought again (Nir et al., 2014). In addition, the external expression of GA oxidase enzyme (GA 2oxidase) improved drought and disease hindrance in rice plants (Lo et al., 2017). SIDREB (drought-reflexing binding protein) also improved drought tolerance in tomatoes by suppressing the genes involved in GA biosynthesis ( $\mathrm{Li}$ et al., 2012a). DELLAs protein factors also primarily regulate response to GA, and this group of nuclear regulators especially act to suppress the GA response. GA binding to the insensitive dwarf1 receptor of GA will result in DELLA degradation, similar to $26 \mathrm{~S}$ proteasome and GA response stimulation (Li et al., 2013).

\section{Abscisic Acid}

Abscisic acid is an important signaling phytohormone under drought stress (De Ollas et al., 2013). Abscisic acid plays a significant role in regulating stomatal closure, gene upregulation and compatible osmolyte synthesis. 9-Neoxanthin cis-epoxicarotenoid dioxygenase (NCED) is used in abscisic acid synthesis and is considered a bottleneck, covering 9neoxanthins to xanthins. This enzyme is used in the upregulation of an increased level of abscisic acid. Abscisic acid is cleaved into $8^{\prime}-\mathrm{OH}-\mathrm{ABA}$, and this process is catalyzed by an ABA $8^{\prime}$-hydroxylase (CYP707A) enzyme. This reaction is used to inactivate abscisic acid. ABA $8^{\prime}$-hydroxylase compounds are spontaneously converted into dehydrophaseic acid (DPA) and phaseic acid (PA), the primary degradation products. Another path that is used to inactivate abscisic acid pools is through conjugation to hexoses catalyzed by the ABA O-glycosyl transferase enzyme. This process yielded the ABA-glycosyl ester (ABAGE) compound (Dong and Hwang, 2014). After the cleavage of the ABA glycosyl ester (ABAGE) compound by an ABA glycosyl ester $\beta$-glycosidase (BG18) enzyme, active abscisic acid is released. Both species have increased levels of phasic acid (PA) and dehydrophaseic acid (DPA) under drought stress, but Cleopatra exhibited a more increased level of ABA-glycosyl ester (ABAGE).

Abscisic acid signaling pathways have vital role in the expression of drought stress-responsive genes because various stress situations can occur in plants. Abscisic acid receptors are very important in the transduction of signals. In the subcellular state, many receptors are recognized. Under normal conditions, $\mathrm{ABA}$ is expressed at low concentrations in plants (Parveen et al., 2021). SnRK2 activity in protein kinases is inhibited by the phosphatase $\mathrm{PP}_{2} \mathrm{C}$, leading to dephosphorylation. As plants develop ABA concentrations, they start to bind with PYRs, PYLs, and RCARs, which bind to deactivate $\mathrm{PP}_{2} \mathrm{C}$ phosphatase activity (Danquah et al., 2014). These PYRs and PYLs are essential receptors for the abscisic acid response encoded by different genes, such as 11 genes in rice and 14 genes in Arabidopsis encoding these receptors (Klingler et al., 2010). The autoactivation of $\mathrm{SnRK}_{2}$ (protein kinases that enhance the abscisic acid response) occurs when the protein is dissociated from phosphatase $\mathrm{PP}_{2} \mathrm{Cs}$ (Hrabak et al., 2003; Ullah et al., 2017), and the rest of the SnRKs are involved in the abscisic acid response (SnRK2.2, SnRK2.3, and SnRK2.6) (Feng et al., 2014). In Arabidopsis, only the A clade participates in the signaling of abscisic acid out of seventy-six $\mathrm{PP}_{2} \mathrm{Cs}$. Additionally, the $\mathrm{ABA}$ signaling pathway is also dependent on branches of various transcription factors, such as MYC, NAC and MYBs. The responsive elements of abscisic acid also play a role in ABA signaling (De Ollas and Dodd, 2016). CDPKs (CDPKs) also proved very important in the pathway related to signaling. Calcium-dependent protein kinases also participate in ABA signaling, and 34 CDPKs have been reported in Arabidopsis, along with 29 in rice, 20 in wheat and 35 in maize. Two CDPKs, CPK4, and CPK11, have been reported to be involved in the regulation of ABA signaling in Arabidopsis. $\mathrm{SnRK}_{2}$ activation triggers the phosphorylation of down-target genes, resulting in the induction of molecular and physiological responses to ABA triggering, such as photosynthetic activity, stomatal regulation, root growth, and germination (Altaf et al., 2020). Abscisic acid also regulates many other genes related to drought stress to develop drought 
tolerance in plants. The abscisic acid-induced pathway is shown in Figure 3.

\section{Salicylic Acid}

The salicylic acid (SA) hormone is associated with drought tolerance and signaling in plants (Miura and Tada, 2014). In response to drought stress, SA biosynthesis takes place via both the isochorismate pathway and the phenylpropanoid pathway. Both pathways require the chemical chorismate generated from the shikimate pathway (Figure 4A). However, the isochorismate pathway is known to be the major pathway in most plants (De Ollas et al., 2013). The phenylpropanoid pathway for SA biosynthesis begins with phenylalanine (Phe) being converted to trans-cinnamic acid ( $\mathrm{t}-\mathrm{CA}$ ) by phenylalanine ammonia lyase (PAL). It is then transformed into benzoic acid (BA). Researchers have yet to discover the enzyme that converts $\mathrm{t}$-CA to benzoic acid. After that, the enzyme benzoic acid 2-hydroxylase catalyzes the hydroxylation reaction that yields SA from BA (BA2H) (Figure 4A). The isochorismate pathway requires enzyme
ICS1 (isochorismate synthase 1) that converts chorismate to isochorismate, and isochorismate is then converted to SA by isochorismate pyruvate lyase (IPL) (Danquah et al., 2014). Salicylic acid also plays a significant role in defense responses against drought stress, as shown in Figure 4B. NPR1 (nonexpresser of pathogenesis-related genes 1 ) is a master regulator of defensive signals mediated by SA. SA binds to NPR1 and NPR1 homologs directly, perhaps regulating NPR1 activity and stability. Increased cellular SA levels cause a redox shift in the cytoplasm, causing NPR1 to transition from oligomer to monomer forms (Figure 4B). The active monomers then go to the nucleus, where SA binds to NPR3 and NPR4 to block their transcriptional repression activity. NPR1 interacts with TGAs (TGACG-binding factors), activating defense responses against drought stress. However, in cells with low SA levels, NPR1 forms oligomers and persists in the cytosol, while NPR3 and NPR4 bind residual NPR1 in the nucleus to block NPR1 function (Figure 4B; Dempsey et al., 2011b). Salicylic acid accumulation in plants improves responses to various abiotic stress conditions, such as drought
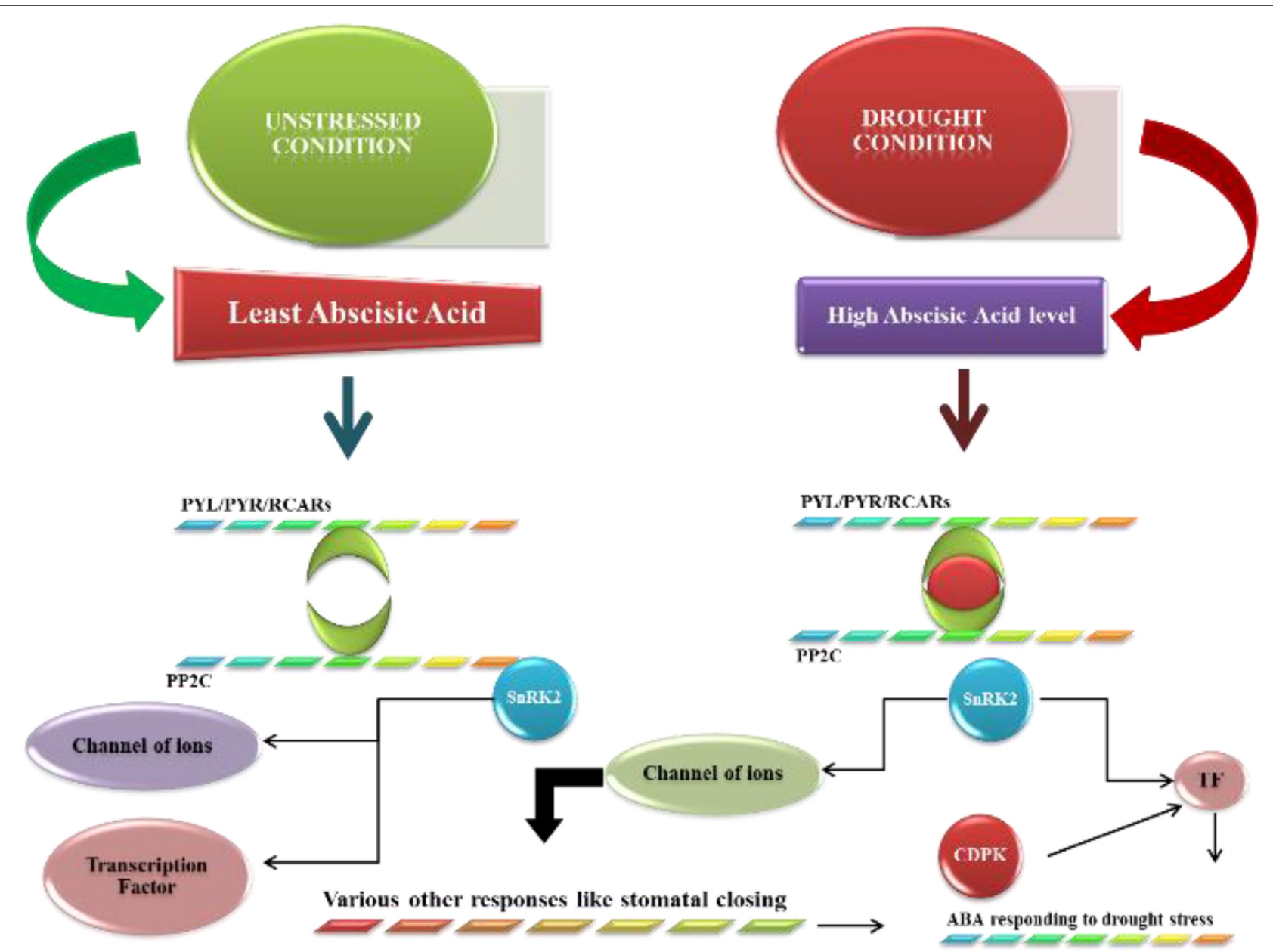

PVI/PYR/RCARs
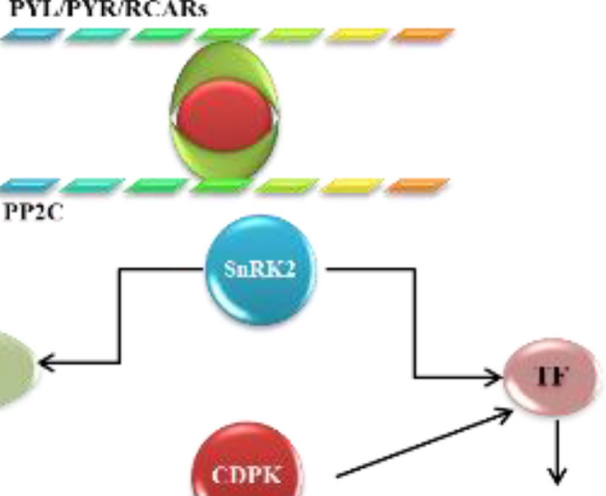

ABA responding to drought stress $\longrightarrow=2=$

FIGURE 3 | ABA's fundamental signaling mechanism during stressful situations. The ABA levels are lower under ideal circumstances, and the function of SnRK2 protein kinase is blocked by PP2C phosphatases. The cellular ABA level rises during high-pressure situations, and ABA then attaches to PYR/PYL/RCARs, which connect to and deactivate PP2Cs in response. If they are detached from PP2C, then SnRK2s are automatically activated. Switched on SnRK2s phosphorylate the following targets and provoke molecular and physiological reactions through ABA. 

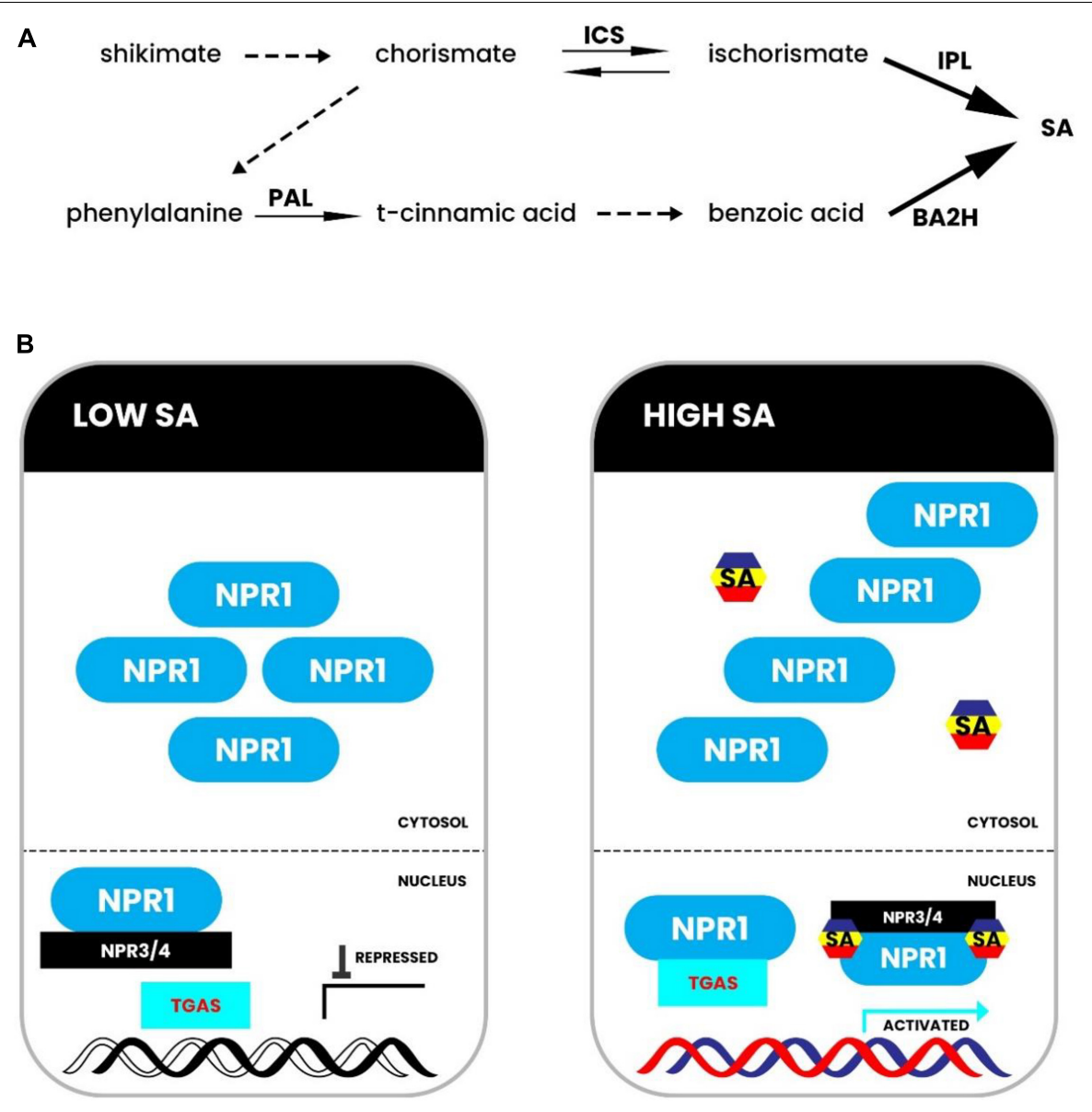

FIGURE 4 | Biosynthesis and signaling of salicylic acid. (A) In Arabidopsis, a model for salicylic acid (SA) production has been proposed. Genetic investigations showed the isochorismate pathway in the upper panel. Biochemical research showed the phenylpropanoid pathway in the lower panel. (B) NPR1 forms an oligomer in the cytosol in cells with low SA levels, and NPR3 and NPR4 bind leftover NPR1 in the nucleus to block NPR1 activity. NPR1 becomes monomeric and reaches the nucleus in cells with high SA levels, where SA binds to NPR3 and NPR4 to disrupt their transcriptional repression action. NPR1 interacts with TGAs in SA-responsive promoters, causing defensive responses to be activated. BA2H stands for benzoic acid 2-hydroxylase; ICS stands for isochorismate synthase; IPL stands for isochorismate pyruvate lyase; NPR stands for non-expresser of pathogenesis-related genes; PAL stands for phenylalanine ammonia lyase; SA stands for salicylic acid; TGA stands for TGACG-binding factor. Adapted from Li et al. (2019).

and salinity (Miura and Tada, 2014), antioxidant activity and photosynthetic machinery protection, which prevents electron leakage (Ismail I. et al., 2020; Malik et al., 2021). Previous studies showed that drought increased endogenous levels of abscisic acid (ABA) and jasmonic acid (JA) in Brassica napus, resulting in a rise in ABA/SA and (ABA + JA)/SA (Lee et al., 2019). The increase of ROS and proline, as well as a loss of reducing potential $[\mathrm{NAD}(\mathrm{P}) \mathrm{H} / \mathrm{NAD}(\mathrm{P})+$ and GSH/GSSG], paralleled the changes in endogenous hormonal balance. Drought-induced $\mathrm{O}_{2}$ buildup was scavenged by SA pretreatment (Lee et al., 2019). Moreover, drought increased ROS generation and, as a result, lipid peroxidation, which is a specific indicator of oxidative damage. On the other hand, Exogenous SA application substantially reduced oxidative damage in rice seedlings in hydroponic and soil systems by upregulating antioxidant enzymes (Ali et al., 2021b). Furthermore, drought stress lowered photosynthetic pigment concentration, gas exchange parameters, proline, soluble sugars, total phenolic, flavonoids, growth, and biomass output. On the other hand, SA promoted Portulaca oleracea growth and biomass production by improving photosynthetic pigments, gas exchanges, suitable solutes, and secondary metabolites (Hamayun et al., 2021a). In Impatiens walleriana, dehydration increased the quantity of electrolyte leakage (EL), malondialdehyde (MDA), peroxidase (POD), and ascorbate peroxidase (APX) activities, along with proline content. P5CR (gene for 1-pyrroline-5carboxylate reductase) has a similar expression pattern to P5CS, with minor changes in intensity. Through improved antioxidant activity and water balance, SA lowered the amount of EL and MDA in the plant (Safari et al., 2021). When compared to non-SA pretreated Brassica rapa, SA pretreatment dramatically boosted proline concentration via upregulating the expression of genes expressing pyrroline-5-carboxylate synthase (P5CSA and $\mathrm{P} 5 \mathrm{CSB}$ ) and down-regulating the expression of the gene encoding proline dehydrogenase $(\mathrm{PDH})$. In another case, the Carrizo citrus plant variety showed greater tolerance to drought and heat stress in combination. Drought stress increased salicylic 
acid levels in the leaves of certain citrus species, such as Carrizo and Cleopatra. Chlorophyll fluorescence, gas exchange parameters and malondialdehyde (MDA) accumulation indicate that Cleopatra mandarin is susceptible to drought and heat stress (Hamayun et al., 2018). Phenotypic traits of citrus plants occur in response to a combination of drought and heat stress. Whole sprouts (\%) of Cleopatra and Carrizo seedlings were exposed to drought and heat stress $\left(40^{\circ} \mathrm{C}\right)$ in combination for 10 days. For each genotype, asterisks denote statistical significance concerning the initial values at $P \leq 0.05$ (Hamayun et al., 2021a).

The salicylic acid levels also increased in plants under drought stress, which may be five times that of the normal level recorded in evergreen shrubby plants in Phillyrea augustifolia (MunnéBosch and Peñuelas, 2003; Hamayun et al., 2021c). The enhanced drought tolerance and disorder resistance found in mutants of Arabidopsis spp. such as $\operatorname{adr}_{1}, \operatorname{acd}_{6}, \mathrm{myb}_{96-1}$, and $\mathrm{cpr}_{5}$ are due to the presence of salicylic acid (Seo and Koshiba, 2011; Miura et al., 2013). In Arabidopsis, stomatal closing was also observed due to salicylic acid accumulation under stressed conditions because the SA-regulated induction of $P R$ gene expression led to drought tolerance by shutting the stomatal openings (Liu et al., 2013; Miura et al., 2013), and stomatal closure occurred through the accumulation of SA under the influence of SIZI in Arabidopsis, significantly increasing the drought tolerance.

In another study, the exogenous application of SA positively regulated ICS1 gene (isochorismate synthase) and enhanced drought tolerance in Arabidopsis. Furthermore, it revealed that SA activated WRKYs and TGAs genes, which then enhanced the plant immune system against drought stress (Klingler et al., 2010).

\section{Jasmonic Acid}

Drought tolerance in plants is induced by closing stomata, shifting reactive oxygen species, and deep root growth in the case of jasmonic acid. Studies have revealed that JAs participate in stomatal closing regulation as a result of drought stress (Riemann et al., 2015). A case study revealed that treating Arabidopsis with 12-OPDA led to stomatal shutting. It is also involved in indirectly decreasing stomatal gaps, favoring drought tolerance. Drought also prevents the alteration of OPDAs to jasmonic acid; in this case, OPDA coupled with ABA or individually leads to the closing of stomata (Savchenko et al., 2014; Kazan, 2015). High ROS foraging was found (Fang et al., 2016) in transgenic plants overexpressing VaNAC26, which showed relatively more drought tolerance. JA-related genes were highly regulated in overexpressed lines under drought and ordinary conditions. The external application of JA led to a perfect reflex by plants to drought stress. External JA application was also shown to enhance the activity of antioxidants under drought stress (Shan et al., 2015). Another case revealed that JA was found to be an enhancer of different enzymes in young wheat, such as ascorbate peroxidases (APX) and ascorbate reductases monodehydroascorbate reductase and glutathione reductase, under stress conditions (Shan et al., 2015). JA also plays a significant role in water conductivity from soil under restricted moisture conditions (De Ollas et al., 2013; Sánchez-Romera et al., 2014) found that the transient presence of jasmonic acid in roots is required under drought stress to increase the abscisic acid levels. However, the function of JA still must be clarified under drought stress to obtain highly tolerant plants. The exogenous application of JA increased the antioxidant activity of plants under drought conditions, as shown in Figure 5. The proteins JAI3/JAZ bind to various transcription factors, including MYC2, and limit their activity under normal conditions. However, during drought stress, the degradation of JAZ proteins occurs, resulting in active transcription factors that upregulate genes of JA, which enhances tolerance in plants against drought stress (De Ollas and Dodd, 2016). Moreover, JA signaling pathways interact with $\mathrm{ABA}$ signaling pathways, suggesting their role in response to drought stress. It has been recently revealed that JA enhanced the hydraulic conductivity of plant roots under drought stress by interacting with calcium and ABA-dependent and independent signaling pathways (De Ollas and Dodd, 2016).

\section{Brassinosteroids}

Brassinosteroids play a role in stress responses along with roles in plant growth and nourishment. These stresses include drought, cold, hypersalinity, metallic heaviness, raised temperature, and infectious agents (Chen et al., 2017). It was previously mentioned that in Arabidopsis, wheat, and Brassica spp., brassinosteroids played a positive role in response to drought stress (Divi et al., 2010). Arabidopsis biosynthetic gene $\left(\mathrm{DWF}_{4}\right)$ overexpression resulted in the appraisal of growth, drought tolerance, and yields (Sahni et al., 2016). By contrast, there was a negative response from the brassinosteroids. Additionally, mutants of Brs showed functional loss, but increased drought tolerance (Northey et al., 2016; Ye et al., 2017), and knocking out $\mathrm{BR}_{1}$ by miRNA technique led to more drought tolerance in Brachypodium distachyon (Feng et al., 2015). These phytohormones play a crucial role in drought stress tolerance. They act synergistically in response to drought stress.

Recently, various WRKY transcription factors have been discovered in Arabidopsis thaliana and these transcription factors are reported to be involved in plant growth and response to drought stress. To regulate plant growth, BRs extensively interact with these transcription factors and GA in response to drought stress (Clarke et al., 2004; Xue et al., 2013; Sánchez-Romera et al., 2014; Sánchez-Martín et al., 2015).

\section{Ethylene}

Ethylene was found to be actively involved in enhancing drought tolerance in plants. In a study on cotton, ethylene-responsive genes or binding protein elements such as $\mathrm{AP}_{2}$, EREBPs, and APETELA $_{2}$ were identified in response to heat and drought stress (Liu and Zhang, 2017). One analysis revealed that members of ERFs (responsive factors of ethylene), $\mathrm{GmERF}_{3}$ isolated from Glycine max, whose expression was induced by drought stress, $\mathrm{ABA}, \mathrm{SA}$, JA, and ET. $\mathrm{GmERF}_{3}$ in overexpressing tobacco plants exhibited more tolerance to drought stress because of the high contents of proline and solubilized sugar compared to wild plants. Transgenic plants showed increased resistance to Ralstonia solancearum, Alternaria alternata, and tobacco mosaic virus due to the high expression of pathogenesis-related protein-coding genes (Hamayun et al., 2019). The overexpression 


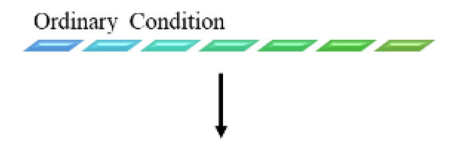

Low Jasmonic Acids level
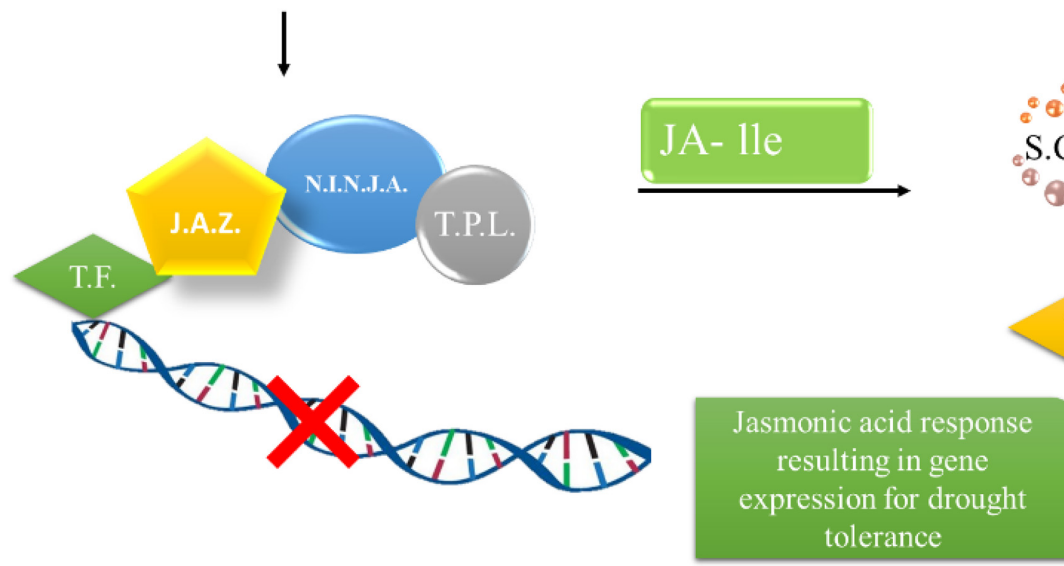

Stressed Condition

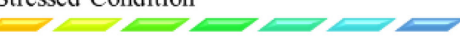

!

High Jasmonic Acid level

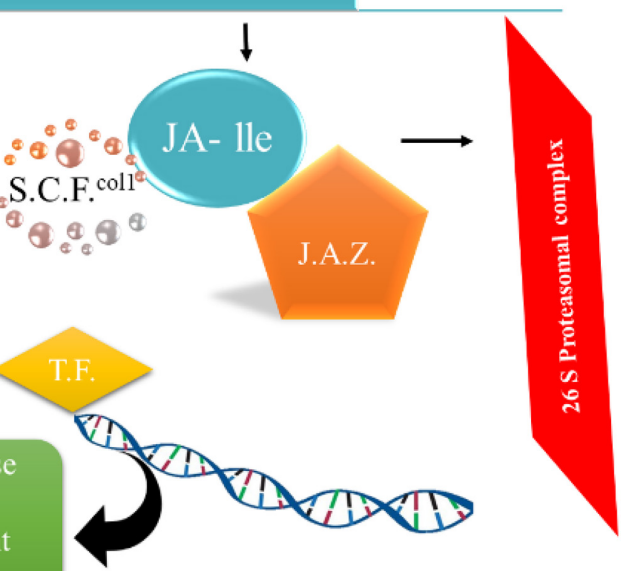

FIGURE 5 | Changes in JA signals under stressful situations. JAI3/JAZ proteins attach to different transcription components and restrict their function along with reduced levels of JA under ideal circumstances. The JA concentrations are high and deteriorate JAZ proteins under stressful situations, leading to the activation of transcriptional components that upregulate genes associated with stress responses.

of the ERF gene (ERF019) in Arabidopsis delayed aging and flowering time. Transgenes also exhibit drought tolerance by lessening transpiration, squeezing the aperture of the stomata, and thinning the cuticle (Scarpeci et al., 2017). In signal transduction, ETR 1 codes for receptors of ET but negatively regulates the response; other receptors of this family always close down the signaling, whether ethylene is present or not (Shi et al., 2016) of the other members of the family include $E R S_{1}, E T R_{2}$, $E I N_{4}$, and $E R S_{2}$. CTR 1 regulates ET signaling. In Arabidopsis, $C T R_{1}$ is involved in ET signaling, while in tomato $3, C T R_{1}$ is involved in ET signaling. There is no evidence of a decrease in the stream substrate of $C T R_{1}$. When the receptor finds ethylene, it shuts off the activity of ethylene, thus leading to a reflex action for tolerance to drought conditions.

\section{Peptides}

Recently several secreted peptides were found to mediate the cellular development in plants. However, it was unclear whether these peptides mediate long-distance signaling in response to drought stress. Among the peptides, CLAVATA3 (CLV3) is a wellcharacterized plant peptide involved in shoot apical meristem formation. In land plants, phytohormone abscisic acid plays a significant role in the regulation of stomatal movement to prevent water loss. However, no mobile signaling molecules have yet been discovered that can enhance the abscisic acid accumulation in leaves (Nir et al., 2014). Recently, CLE25 peptide was found to transmit water-deficiency signals through vascular tissues in Arabidopsis and affects abscisic acid biosynthesis and stomatal control of transpiration. The gene related to these peptides was expressed in the vascular tissues and enhanced root response to drought stress. These peptides move from the roots to the leaves and induce stomatal closure by modulating abscisic acid accumulation, enhancing resistance to drought stress. Recently, another peptide gene in rice, OsDSSR1, was discovered, which was expressed mainly in the root, stem, node, leaf, and panicle, and this expression was induced by drought stress. The peptide is localized in the nucleus and cytoplasm and exhibited enhanced drought stress tolerance and decreased ABA sensitivity compared to the wild type (Yu et al., 2016). Other peptides such as phytosulfokine (PSK), a growth related to cell proliferation; rapid alkalinization factor (RALF), which regulates root growth; LUREs, which guides pollen tube growth; STOMAGEN, which is related to stomatal development; and casparian strip integrity factor (CIF), which is associated with the formation of the casparian strip diffusion barrier; Another peptide, AtPep3 which plays an important role in the drought and salinity stresses were also recently discovered (Nir et al., 2014; Liang et al., 2016; Yu et al., 2016).

\section{CONCLUSION AND FUTURE PERSPECTIVES}

An ever-growing population and diminishing natural resources have made it difficult for farmers to produce enough food to meet their needs. Drought is a major constraint on crop productivity worldwide and is expected to worsen in the near future. Besides, droughts are becoming more 
common, severe, and widespread due to climate change. Hence, scientists are attempting to develop drought-tolerant crops and understand different drought tolerance mechanisms. This review's underlying theme is that plants typically respond to drought stress by adjusting the levels of phytohormones, such as abscisic acid, jasmonic acid, auxin, ethylene, and gibberellin, cytokinin, brassinosteroids, and small peptide molecules. These phytohormones trigger tolerance to drought stress via regulation of various morphological, physiological, biochemical and molecular processes. The morphological and physiological processes involve changes in the composition of the leaves, root growth and stomatal control. The biochemical process includes adjusting the levels of phytohormones. Molecular processes include phytohormone-mediated signals, leading to the activation of various transcription factors that causes the expression of genes required for plant survival in drought stress (Saleem et al., 2020).

However, due to the high level of complexity, most of the mechanisms by which phytohormones trigger drought tolerance in crops are poorly understood and requires further study. Besides, scientists could not comprehend the crosstalk among the phytohormones against drought stress. Since crosstalk is so intricate, the underlying mechanisms are also unknown and need further investigation. Recently scientists are attempting to understand the mechanisms of drought tolerance in plants through the exogenous application of phytohormones. In addition, drought stress in plants is alleviated by applying plant

\section{REFERENCES}

Ali, M., Afzal, S., Parveen, A., Kamran, M., Javed, M. R., Abbasi, G. H., et al. (2021a). Silicon mediated improvement in the growth and ion homeostasis by decreasing $\mathrm{Na}+$ uptake in maize (Zea mays L.) cultivars exposed to salinity stress. Plant Physiol. Biochem. 158, 208-218. doi: 10.1016/j.plaphy.2020.10.040

Ali, M., Kamran, M., Abbasi, G. H., Saleem, M. H., Ahmad, S., Parveen, A., et al. (2021b). Melatonin-induced salinity tolerance by ameliorating osmotic and oxidative stress in the seedlings of two tomato (Solanum lycopersicum L.) cultivars. J. Plant Growth Regulat. 40, 2236-2248.

Altaf, M. A., Shahid, R., Ren, M. X., Mora-Poblete, F., Arnao, M. B., Naz, S., et al. (2020). Phytomelatonin: an overview of the importance and mediating functions of melatonin against environmental stresses. Physiol. Plant. 172, 820-846. doi: 10.1111/ppl.13262

Asgher, M., Khan, M. I., Anjum, N. A., and Khan, N. A. (2015). Minimising toxicity of cadmium in plants-role of plant growth regulators. Protoplasma 252, 399-413. doi: 10.1007/s00709-014-0710-4

Bouzroud, S., Gouiaa, S., Hu, N., Bernadac, A., Mila, I., Bendaou, N., et al. (2018). Auxin response factors (ARFs) are potential mediators of auxin action in tomato response to biotic and abiotic stress (Solanum lycopersicum). PLoS One 13:e0193517. doi: 10.1371/journal.pone.0193517

Cao, F. Y., Yoshioka, K., and Desveaux, D. (2011). The roles of ABA in plantpathogen interactions. J. Plant Res. 124, 489-499. doi: 10.1007/s10265-0110409-y

Chen, J., Nolan, T. M., Ye, H., Zhang, M., Tong, H., Xin, P., et al. (2017). Arabidopsis WRKY46, WRKY54, and WRKY70 Transcription Factors Are Involved in Brassinosteroid-Regulated Plant Growth and Drought Responses. Plant Cell 29, 1425-1439. doi: 10.1105/tpc.17.00364

Ciura, J., and Kruk, J. (2018). Phytohormones as targets for improving plant productivity and stress tolerance. J. Plant Physiol. 229, 32-40. doi: 10.1016/j. jplph.2018.06.013

Clarke, S. M., Mur, L. A., Wood, J. E., and Scott, I. M. (2004). Salicylic acid dependent signaling promotes basal thermotolerance but is not essential for microbiomes. These plant microbiomes induce drought stressresponsive genes and play a crucial role in the acquisition of drought tolerance (Ismail A. H. et al., 2020). In the future, newly developed large-scale OMIC methods and highthroughput bioinformatic analysis will be used to seek a better understanding of the mechanisms by which phytohormones trigger drought tolerance in crops, which will ultimately lead to the development of drought-resistant crop plants with significant agronomic features.

\section{AUTHOR CONTRIBUTIONS}

SI, XW, IM, and MK wrote the manuscript. SI, MK, and XW designed the study idea and applied the mode. GD, AP, SF, $\mathrm{HA}, \mathrm{TZ}$, and AA collected and arranged the whole database. $\mathrm{AA}, \mathrm{IK}, \mathrm{MK}$, and MNA analyzed and discussed the contents of the manuscript. SF, MK, IK, and SI critically revised the manuscript. All authors contributed to the article and approved the submitted version.

\section{FUNDING}

This research was funded by the National Natural Science Foundation (51809224). The APC was funded by the National Natural Science Foundation (51809224).

acquired thermotolerance in Arabidopsis thaliana. Plant J. 38, 432-447. doi: 10.1111/j.1365-313X.2004.02054.x

Colebrook, E. H., Thomas, S. G., Phillips, A. L., and Hedden, P. (2014b). The role of gibberellin signalling in plant responses to abiotic stress. J. Exp. Biol. 217, 67-75. doi: $10.1242 /$ jeb.089938

Colebrook, E. H., Thomas, S. G., Phillips, A. L., and Hedden, P. (2014a). The role of gibberellin signalling in plant responses to abiotic stress. J. Exp. Biol. 217, 67-75.

Danquah, A., De Zelicourt, A., Colcombet, J., and Hirt, H. (2014). The role of $\mathrm{ABA}$ and MAPK signaling pathways in plant abiotic stress responses. Biotechnol. Adv. 32, 40-52. doi: 10.1016/j.biotechadv.2013.0 9.006

De Ollas, C., and Dodd, I. C. (2016). Physiological impacts of ABA-JA interactions under water-limitation. Plant Mol. Biol. 91, 641-650. doi: 10.1007/s11103-0160503-6

De Ollas, C., Hernando, B., Arbona, V., and Gómez-Cadenas, A. (2013). Jasmonic acid transient accumulation is needed for abscisic acid increase in citrus roots under drought stress conditions. Physiol. Plant 147, 296-306. doi: 10.1111/j. 1399-3054.2012.01659.x

Dempsey, D. A., Vlot, A. C., Wildermuth, M. C., and Klessig, D. F. (2011b). Salicylic Acid biosynthesis and metabolism. Arabidopsis Book 9:e0156.

Dempsey, D., Vlot, A., Wildermuth, M., and Klessig, D. (2011a). The Arabidopsis Book. Rockville MD: The American Society of Plant Biologists, e0156.

Divi, U. K., Rahman, T., and Krishna, P. (2010). Brassinosteroid-mediated stress tolerance in Arabidopsis shows interactions with abscisic acid, ethylene and salicylic acid pathways. BMC Plant Biol. 10:151. doi: 10.1186/1471-2229-1 $0-151$

Dong, T., and Hwang, I. (2014). Contribution of ABA UDP-glucosyltransferases in coordination of ABA biosynthesis and catabolism for ABA homeostasis. Plant Signal Behav. 9:e28888. doi: 10.4161/psb.28888

Dubois, M., Van Den Broeck, L., and Inzé, D. (2018). The Pivotal Role of Ethylene in Plant Growth. Trends Plant Sci. 23, 311-323. doi: 10.1016/j.tplants.2018. 01.003 
Fahad, S., Bajwa, A. A., Nazir, U., Anjum, S. A., Farooq, A., Zohaib, A., et al. (2017). Crop production under drought and heat stress: Plant responses and Management Options. Front. Plant Sci. 8:1147. doi: 10.3389/fpls.2017.01147

Fahad, S., Muhammad, Z. I., Abdul, K., Ihsanullah, D., Saud, S., Saleh, A., et al. (2018). Consequences of high temperature under changing climate optima for rice pollen characteristics-concepts and perspectives. Archives Agron. Soil Sci. 2018:1443213. doi: $10.1080 / 03650340.2018 .1443213$

Fahad, S., Nie, L., Chen, Y., Wu, C., Xiong, D., Saud, S., et al. (2015). Crop plant hormones and environmental stress. Sustain Agric. Rev. 15, 371-400.

Fahad, S., Hasanuzzaman, M., Alam, M., Ullah, H., Saeed, M., Ali, K. I., et al. (eds) (2020). Environment, Climate, Plant and Vegetation Growth. New York, NY: Springer Nature, doi: 10.1007/978-3-030-49732-3

Fahad, S., Sönmez, O., Saud, S., Wang, D., Wu, C., Adnan, M., et al. (eds) (2021a). Plant growth regulators for climate-smart agriculture, First edition. ed, Footprints of climate variability on plant diversity. Boca Raton, FL: CRC Press.

Fahad, S., Sonmez, O., Saud, S., Wang, D., Wu, C., Adnan, M., et al. (eds) (2021b). Climate change and plants: biodiversity, growth and interactions, First edition. ed, Footprints of climate variability on plant diversity. Boca Raton, FL: CRC Press.

Fahad, S., Sonmez, O., Saud, S., Wang, D., Wu, C., Adnan, M., et al. (eds) (2021c). Developing climate resilient crops: improving global food security and safety, First edition. ed, Footprints of climate variability on plant diversity. Boca Raton, FL: CRC Press.

Fahad, S., Sönmez, O., Turan, V., Adnan, M., Saud, S., Wu, C., et al. (eds) (2021d). Sustainable soil and land management and climate change, First edition. ed, Footprints of climate variability on plant diversity. Boca Raton, FL: CRC Press.

Fahad, S., Sönmez, O., Saud, S., Wang, D., Wu, C., Adnan, M., et al. (eds) (2021e). Engineering Tolerance in Crop Plants Against Abiotic Stress, First edition. ed, Footprints of climate variability on plant diversity. Boca Raton, FL: CRC Press.

Fahad, S., Saud, S., Yajun, C., Chao, W., and Depeng, W. (eds) (2021f). Abiotic stress in plants. London: IntechOpen United Kingdom, doi: 10.5772/intechopen. 91549

Fang, L., Su, L., Sun, X., Li, X., Sun, M., Karungo, S. K., et al. (2016). Expression of Vitis amurensis NAC26 in Arabidopsis enhances drought tolerance by modulating jasmonic acid synthesis. J. Exp. Bot. 67, 2829-2845. doi: 10.1093/ jxb/erw122

Farrow, S. C., and Facchini, P. J. (2014). Functional diversity of 2oxoglutarate/ $\mathrm{Fe}(\mathrm{II})$-dependent dioxygenases in plant metabolism. Front. Plant Sci. 5:524. doi: 10.3389/fpls.2014.00524

Feng, C. Z., Chen, Y., Wang, C., Kong, Y. H., Wu, W. H., and Chen, Y. F. (2014). Arabidopsis RAV1 transcription factor, phosphorylated by SnRK2 kinases, regulates the expression of $\mathrm{ABI} 3, \mathrm{ABI} 4$, and $\mathrm{ABI} 5$ during seed germination and early seedling development. Plant J. 80, 654-668. doi: 10.1111/tpj.12670

Feng, Y., Yin, Y., and Fei, S. (2015). Down-regulation of BdBRI1, a putative brassinosteroid receptor gene produces a dwarf phenotype with enhanced drought tolerance in Brachypodium distachyon. Plant Sci. 234, 163-173. doi: 10.1016/j.plantsci.2015.02.015

Floková, K., Tarkowská, D., Miersch, O., Strnad, M., Wasternack, C., and Novák, O. (2014). UHPLC-MS/MS based target profiling of stress-induced phytohormones. Phytochemistry 105, 147-157. doi: 10.1016/j.phytochem.2014. 05.015

Fuller, D. Q., and Stevens, C. J. (2019). Between domestication and civilization: the role of agriculture and arboriculture in the emergence of the first urban societies. Veg. Hist. Archaeobot. 28, 263-282. doi: 10.1007/s00334-019-00727-4

Ha, S., Vankova, R., Yamaguchi-Shinozaki, K., Shinozaki, K., and Tran, L.S. P. (2012). Cytokinins: metabolism and function in plant adaptation to environmental stresses. Trends Plant Sci. 17, 172-179. doi: 10.1016/j.tplants. 2011.12.005

Hamayun, M., Hussain, A., Iqbal, A., Khan, S. A., and Lee, I.-J. (2018). Endophytic fungus Aspergillus japonicus mediates host plant growth under normal and heat stress conditions. BioMed Res. Internat. 2018:2018. doi: 10.1155/2018/7696831

Hamayun, M., Hussain, A., Afzal Khan, S., Iqbal, A., and Lee, I.-J. (2019). Aspergillus flavus promoted the growth of soybean and sunflower seedlings at elevated temperature. BioMed. Res. Internat. 1:2019. doi: 10.1155/2019/ 1295457

Hamayun, M., Hussain, A., Iqbal, A., Khan, S. A., Khan, M. A., and Lee, I.-J. (2021c). An Endophytic Fungus Gliocladium cibotii Regulates Metabolic and Antioxidant System of Glycine max and Helianthus annuus under Heat Stress. Polish J. Env. Stud. 2021:30.
Hamayun, M., Hussain, A., Iqbal, A., Khan, S. A., Gul, S., Khan, H., et al. (2021b). Penicillium Glabrum Acted as a Heat Stress Relieving Endophyte in Soybean and Sunflower. Polish J. Env. Stud. 2021:30.

Hamayun, M., Hussain, A., Iqbal, A., Khan, S. A., Ahmad, A., Gul, S., et al. (2021a). Aspergillus foetidus regulated the biochemical characteristics of soybean and sunflower under heat stress condition: role in sustainability. Sustainability 13:7159.

Hrabak, E. M., Chan, C. W., Gribskov, M., Harper, J. F., Choi, J. H., Halford, N., et al. (2003). The Arabidopsis CDPK-SnRK superfamily of protein kinases. Plant Physiol. 132, 666-680. doi: 10.1104/pp.102.011999

Hu, L., Wang, J., Yang, C., Islam, F., Bouwmeester, H. J., Muños, S., et al. (2020). The Effect of Virulence and Resistance Mechanisms on the Interactions between Parasitic Plants and Their Hosts. Int. J. Mol. Sci. 2020:21. doi: 10.3390/ ijms 21239013

Hu, W., Ren, T., Meng, F., Cong, R., Li, X., White, P. J., et al. (2019). Leaf photosynthetic capacity is regulated by the interaction of nitrogen and potassium through coordination of $\mathrm{CO}(2)$ diffusion and carboxylation. Physiol. Plant 167, 418-432. doi: 10.1111/ppl.12919

Im Kim, J., Baek, D., Park, H. C., Chun, H. J., Oh, D.-H., Lee, M. K., et al. (2013). Overexpression of Arabidopsis YUCCA6 in potato results in high-auxin developmental phenotypes and enhanced resistance to water deficit. Molecular plant 6, 337-349. doi: $10.1093 / \mathrm{mp} / \mathrm{sss} 100$

Ismail, I., Hamayun, M., Hussain, A., Iqbal, A., Khan, S. A., and Lee, I.-J. (2020). Aspergillus niger boosted heat stress tolerance in sunflower and soybean via regulating their metabolic and antioxidant system. J. Plant Interact. 15, 223-232.

Ismail, A. H., Mehmood, A., Qadir, M., Husna, A. I., Hamayun, M., and Khan, N. (2020). Thermal stress alleviating potential of endophytic fungus rhizopus oryzae inoculated to sunflower (Helianthus annuus L.) and soybean (Glycine max L.). Pak. J. Bot. 52, 1857-1865.

Ismail, H. M., Anwar, H., Sumera, A. K., Amjad, I., and In-Jung, L. (2020). An endophytic fungus Aspergillus violaceofuscus can be used as heat stress adaptive tool for Glycine max L. and Helianthus annuus. L. J. Appl. Bot. Food Q. 93:112.

Jiang, K., and Asami, T. (2018). Chemical regulators of plant hormones and their applications in basic research and agriculture. Biosci. Biotechnol. Biochem. 82, 1265-1300. doi: 10.1080/09168451.2018.1462693

Jung, H., Lee, D.-K., Do Choi, Y., and Kim, J.-K. (2015). OsIAA6, a member of the rice Aux/IAA gene family, is involved in drought tolerance and tiller outgrowth. Plant Sci. 236, 304-312. doi: 10.1016/j.plantsci.2015.04.018

Kamran, M., Danish, M., Saleem, M. H., Malik, Z., Parveen, A., Abbasi, G. H., et al. (2021). Application of abscisic acid and 6-benzylaminopurine modulated morpho-physiological and antioxidative defense responses of tomato (Solanum lycopersicum L.) by minimizing cobalt uptake. Chemosphere 263:128169. doi: 10.1016/j.chemosphere.2020.128169

Kamran, M., Malik, Z., Parveen, A., Zong, Y., Abbasi, G. H., Rafiq, M. T., et al. (2019). Biochar alleviates $\mathrm{Cd}$ phytotoxicity by minimizing bioavailability and oxidative stress in pak choi (Brassica chinensis L.) cultivated in Cdpolluted soil. J. Env. Manag. 250:109500. doi: 10.1016/j.jenvman.2019.10 9500

Kang, S.-M., Hamayun, M., Khan, M. A., Iqbal, A., and Lee, I.-J. (2019). Bacillus subtilis JW1 enhances plant growth and nutrient uptake of Chinese cabbage through gibberellins secretion. J. Appl. Bot. Food Qual. 92, 172-178.

Kazan, K. (2013). Auxin and the integration of environmental signals into plant root development. Ann. Bot. 112, 1655-1665. doi: 10.1093/aob/mct229

Kazan, K. (2015). Diverse roles of jasmonates and ethylene in abiotic stress tolerance. Trends Plant Sci. 20, 219-229. doi: 10.1016/j.tplants.2015.02.001

Ke, M., Zheng, Y., and Zhu, Z. (2015). Rethinking the origin of auxin biosynthesis in plants. Front. Plant Sci. 6:1093. doi: 10.3389/fpls.2015.01093

Klingler, J. P., Batelli, G., and Zhu, J.-K. (2010). ABA receptors: the START of a new paradigm in phytohormone signalling. J. Exp. Bot. 61, 3199-3210. doi: 10.1093/jxb/erq151

Lee, B.-R., Zhang, Q., Park, S.-H., Islam, M. T., and Kim, T.-H. (2019). Salicylic acid improves drought-stress tolerance by regulating the redox status and proline metabolism in Brassica rapa. Horticult. Env. Biotechnol. 60, 31-40.

Li, N., Han, X., Feng, D., Yuan, D., and Huang, L. J. (2019). Signaling Crosstalk between Salicylic Acid and Ethylene/Jasmonate in Plant Defense: Do We Understand What They Are Whispering? Int. J. Mol. Sci. 2019:20. doi: 10.3390/ ijms20030671 
Li, Q. F., Wang, C., Jiang, L., Li, S., Sun, S. S., and He, J. X. (2012c). An interaction between BZR1 and DELLAs mediates direct signaling crosstalk between brassinosteroids and gibberellins in Arabidopsis. Sci Signal 5:ra72. doi: 10.1126/scisignal.2002908

Li, J., Sima, W., Ouyang, B., Wang, T., Ziaf, K., Luo, Z., et al. (2012a). Tomato SIDREB gene restricts leaf expansion and internode elongation by downregulating key genes for gibberellin biosynthesis. J. Exp. Bot. 63, 64076420. doi: 10.1093/jxb/ers295

Li, Q.-F., Wang, C., Jiang, L., Li, S., Sun, S. S., and He, J.-X. (2012b). An interaction between BZR1 and DELLAs mediates direct signaling crosstalk between brassinosteroids and gibberellins in Arabidopsis. Sci. Signal. 5, ra72ra72.

Li, W., Herrera-Estrella, L., and Tran, L. P. (2016). The Yin-Yang of Cytokinin Homeostasis and Drought Acclimation/Adaptation. Trends Plant Sci. 21, 548550. doi: 10.1016/j.tplants.2016.05.006

Li, Y., Zhang, J., Zhang, J., Hao, L., Hua, J., Duan, L., et al. (2013). Expression of an A rabidopsis molybdenum cofactor sulphurase gene in soybean enhances drought tolerance and increases yield under field conditions. Plant Biotechnol. J. 11, 747-758. doi: 10.1111/pbi.12066

Liang, C., Meng, Z., Meng, Z., Malik, W., Yan, R., Lwin, K. M., et al. (2016). GhABF2, a bZIP transcription factor, confers drought and salinity tolerance in cotton (Gossypium hirsutum L.). Sci. Rep. 6, 1-14. doi: 10.1038/srep35040

Lim, C. W., Baek, W., Jung, J., Kim, J.-H., and Lee, S. C. (2015). Function of ABA in stomatal defense against biotic and drought stresses. Internat. J. Mole. Sci. 16, 15251-15270. doi: 10.3390/ijms160715251

Liu, C., and Zhang, T. (2017). Expansion and stress responses of the AP2/EREBP superfamily in cotton. BMC Genom. 18:118. doi: 10.1186/s12864-017-3517-9

Liu, J., Feng, K., Hou, X., Li, H., Wang, G., Xu, Z., et al. (2019). Transcriptome profiling reveals the association of multiple genes and pathways contributing to hormonal control in celery leaves. Acta Biochim. Biophys. Sin. 51, 524-534. doi: 10.1093/abbs/gmz034

Liu, P., Xu, Z. S., Pan-Pan, L., Hu, D., Chen, M., Li, L. C., et al. (2013). A wheat PI4K gene whose product possesses threonine autophophorylation activity confers tolerance to drought and salt in Arabidopsis. J. Exp. Bot. 64, 2915-2927. doi: 10.1093/jxb/ert133

Liu, Y. N., Xi, M., Zhang, X. L., Yu, Z. D., and Kong, F. L. (2019). [Carbon storage distribution characteristics of wetlands in China and its influencing factors.]. Ying Yong Sheng Tai Xue Bao 30, 2481-2489. doi: 10.13287/j.1001-9332.2019 07.036

Ljung, K. (2013). Auxin metabolism and homeostasis during plant development. Development 140, 943-950. doi: 10.1242/dev.086363

Lo, S. F., Ho, T. D., Liu, Y. L., Jiang, M. J., Hsieh, K. T., Chen, K. T., et al. (2017). Ectopic expression of specific GA2 oxidase mutants promotes yield and stress tolerance in rice. Plant Biotechnol. J. 15, 850-864. doi: 10.1111/pbi.12681

Malik, Z., Afzal, S., Dawood, M., Abbasi, G. H., Khan, M. I., Kamran, M., et al. (2021). Exogenous melatonin mitigates chromium toxicity in maize seedlings by modulating antioxidant system and suppresses chromium uptake and oxidative stress. Environ. Geochem Health 2021, 1-19. doi: 10.1007/s10653-02100908-z

Mao, C., He, J., Liu, L., Deng, Q., Yao, X., Liu, C., et al. (2020). OsNAC2 integrates auxin and cytokinin pathways to modulate rice root development. Plant Biotechnol. J. 18, 429-442. doi: 10.1111/pbi.13209

Miller, C. O. (1961). A kinetin-like compound in maize. Proc. Natl. Acad. Sci. U S A 47, 170-174. doi: 10.1073/pnas.47.2.170

Miura, K., Okamoto, H., Okuma, E., Shiba, H., Kamada, H., Hasegawa, P. M., et al. (2013). SIZ1 deficiency causes reduced stomatal aperture and enhanced drought tolerance via controlling salicylic acid-induced accumulation of reactive oxygen species in Arabidopsis. Plant J. 73, 91-104. doi: 10.1111/tpj.12014

Miura, K., and Tada, Y. (2014). Regulation of water, salinity, and cold stress responses by salicylic acid. Front. Plant Sci. 5:4. doi: 10.3389/fpls.2014.00004

Munne-Bosch, S., and Penuelas, J. (2003). Photo-and antioxidative protection, and a role for salicylic acid during drought and recovery in field-grown Phillyrea angustifolia plants. Planta 217, 758-766. doi: 10.1007/s00425-003-1037-0

Munné-Bosch, S., and Peñuelas, J. (2003). Photo- and antioxidative protection, and a role for salicylic acid during drought and recovery in field-grown Phillyrea angustifolia plants. Planta $217,758-766$.

Nir, I., Moshelion, M., and Weiss, D. (2014). The Arabidopsis gibberellin methyl transferase 1 suppresses gibberellin activity, reduces whole-plant transpiration and promotes drought tolerance in transgenic tomato. Plant Cell Environ. 37, 113-123. doi: 10.1111/pce.12135

Nishiyama, R., Watanabe, Y., Fujita, Y., Le, D. T., Kojima, M., Werner, T., et al. (2011). Analysis of cytokinin mutants and regulation of cytokinin metabolic genes reveals important regulatory roles of cytokinins in drought, salt and abscisic acid responses, and abscisic acid biosynthesis. Plant Cell 23, 2169-2183. doi: 10.1105/tpc.111.087395

Nishiyama, R., Watanabe, Y., Leyva-Gonzalez, M. A., Van Ha, C., Fujita, Y., Tanaka, M., et al. (2013). Arabidopsis AHP2, AHP3, and AHP5 histidine phosphotransfer proteins function as redundant negative regulators of drought stress response. PNAS 110, 4840-4845. doi: 10.1073/pnas.1302265110

Northey, J. G., Liang, S., Jamshed, M., Deb, S., Foo, E., Reid, J. B., et al. (2016). Farnesylation mediates brassinosteroid biosynthesis to regulate abscisic acid responses. Nat. Plants 2:16114. doi: 10.1038/nplants.2016.114

Nowicka, B., Ciura, J., Szymañska, R., and Kruk, J. (2018). Improving photosynthesis, plant productivity and abiotic stress tolerance - current trends and future perspectives. J. Plant Physiol. 231, 415-433. doi: 10.1016/j.jplph.2018. 10.022

Parveen, A., Ahmar, S., Kamran, M., Malik, Z., Ali, A., Riaz, M., et al. (2021). Abscisic acid signaling reduced transpiration flow, regulated $\mathrm{Na}+$ ion homeostasis and antioxidant enzyme activities to induce salinity tolerance in wheat (Triticum aestivum L.) seedlings. Env. Technol. Innov. 24:101808.

Parveen, A., Saleem, M. H., Kamran, M., Haider, M. Z., Chen, J.-T., Malik, Z., et al. (2020). Effect of citric acid on growth, ecophysiology, chloroplast ultrastructure, and phytoremediation potential of jute (Corchorus capsularis L.) seedlings exposed to copper stress. Biomolecules 10:592. doi: 10.3390/biom10040592

Péret, B., Middleton, A. M., French, A. P., Larrieu, A., Bishopp, A., Njo, M., et al. (2013). Sequential induction of auxin efflux and influx carriers regulates lateral root emergence. Mol. Syst. Biol. 9:699. doi: 10.1038/msb.2013.43

Riaz, M., Kamran, M., Fang, Y., Wang, Q., Cao, H., Yang, G., et al. (2021). Arbuscular mycorrhizal fungi-induced mitigation of heavy metal phytotoxicity in metal contaminated soils: a critical review. J. Hazard. Material. 402:123919. doi: 10.1016/j.jhazmat.2020.123919

Riemann, M., Dhakarey, R., Hazman, M., Miro, B., Kohli, A., and Nick, P. (2015). Exploring Jasmonates in the Hormonal Network of Drought and Salinity Responses. Front. Plant Sci. 6:1077. doi: 10.3389/fpls.2015.01077

Rizwan, M., Ali, S., Ibrahim, M., Farid, M., Adrees, M., Bharwana, S. A., et al. (2015). Mechanisms of silicon-mediated alleviation of drought and salt stress in plants: a review. Environ. Sci. Pollut. Res. Int. 22, 15416-15431. doi: 10.1007/ s11356-015-5305-x

Safari, M., Mousavi-Fard, S., Nejad, A. R., Sorkheh, K., and Sofo, A. (2021). Exogenous salicylic acid positively affects morpho-physiological and molecular responses of Impatiens walleriana plants grown under drought stress. Internat. J. Env. Sci. Technol. 2021, 1-16.

Sah, S. K., Reddy, K. R., and Li, J. (2016). Abscisic Acid and Abiotic Stress Tolerance in Crop Plants. Front. Plant Sci. 7:571. doi: 10.3389/fpls.2016.00571

Sahni, S., Prasad, B. D., Liu, Q., Grbic, V., Sharpe, A., Singh, S. P., et al. (2016). Overexpression of the brassinosteroid biosynthetic gene DWF4 in Brassica napus simultaneously increases seed yield and stress tolerance. Sci. Rep. 6:28298. doi: 10.1038/srep28298

Saleem, M. H., Ali, S., Kamran, M., Iqbal, N., Azeem, M., Tariq Javed, M., et al. (2020). Ethylenediaminetetraacetic acid (EDTA) mitigates the toxic effect of excessive copper concentrations on growth, gaseous exchange and chloroplast ultrastructure of Corchorus capsularis L. and Improves copper accumulation capabilities. Plants 9:756. doi: 10.3390/plants9060756

Sánchez-Martín, J., Heald, J., Kingston-Smith, A., Winters, A., Rubiales, D., Sanz, M., et al. (2015). A metabolomic study in oats (Avena sativa) highlights a drought tolerance mechanism based upon salicylate signalling pathways and the modulation of carbon, antioxidant and photo-oxidative metabolism. Plant Cell Environ. 38, 1434-1452. doi: 10.1111/pce.12501

Sánchez-Romera, B., Ruiz-Lozano, J. M., Li, G., Luu, D. T., Martínez-Ballesta Mdel, C., Carvajal, M., et al. (2014). Enhancement of root hydraulic conductivity by methyl jasmonate and the role of calcium and abscisic acid in this process. Plant Cell Environ. 37, 995-1008. doi: 10.1111/pce.12214

Savchenko, T., Kolla, V. A., Wang, C. Q., Nasafi, Z., Hicks, D. R., Phadungchob, B., et al. (2014). Functional convergence of oxylipin and abscisic acid pathways controls stomatal closure in response to drought. Plant Physiol. 164, 1151-1160. doi: $10.1104 /$ pp.113.234310 
Scarpeci, T. E., Frea, V. S., Zanor, M. I., and Valle, E. M. (2017). Overexpression of AtERF019 delays plant growth and senescence, and improves drought tolerance in Arabidopsis. J. Exp. Bot. 68, 673-685. doi: 10.1093/jxb/erw429

Seo, M., and Koshiba, T. (2011). Transport of ABA from the site of biosynthesis to the site of action. J. Plant Res. 124, 501-507. doi: 10.1007/s10265-011-0411-4

Shan, C., Zhou, Y., and Liu, M. (2015). Nitric oxide participates in the regulation of the ascorbate-glutathione cycle by exogenous jasmonic acid in the leaves of wheat seedlings under drought stress. Protoplasma 252, 1397-1405. doi: 10.1007/s00709-015-0756-y

Shi, J., Drummond, B. J., Wang, H., Archibald, R. L., and Habben, J. E. (2016). Maize and Arabidopsis ARGOS Proteins Interact with Ethylene Receptor Signaling Complex, Supporting a Regulatory Role for ARGOS in Ethylene Signal Transduction. Plant Physiol. 171, 2783-2797. doi: 10.1104/pp.16.00347

Shi, S., Li, S., Asim, M., Mao, J., Xu, D., Ullah, Z., et al. (2018). The Arabidopsis Calcium-Dependent Protein Kinases (CDPKs) and Their Roles in Plant Growth Regulation and Abiotic Stress Responses. Int. J. Mol. Sci. 2018:19. doi: 10.3390/ ijms 19071900

Stec, N., Banasiak, J., and Jasiñski, M. (2016). Abscisic acid - an overlooked player in plant-microbe symbioses formation? Acta Biochim. Pol. 63, 53-58. doi: 10.18388/abp.2015_1210

Teixeira, P. J. P., Colaianni, N. R., Fitzpatrick, C. R., and Dangl, J. L. (2019). Beyond pathogens: microbiota interactions with the plant immune system. Curr. Opin. Microbiol. 49, 7-17. doi: 10.1016/j.mib.2019.08.003

Ullah, A., Manghwar, H., Shaban, M., Khan, A. H., Akbar, A., Ali, U., et al. (2018). Phytohormones enhanced drought tolerance in plants: a coping strategy. Environ. Sci. Pollut. Res. Int. 25, 33103-33118. doi: 10.1007/s11356-018-3364-5

Ullah, A., Sun, H., Yang, X., and Zhang, X. (2017). Drought coping strategies in cotton: increased crop per drop. Plant Biotechnol. J. 15, 271-284. doi: 10.1111/ pbi. 12688

Verma, V., Ravindran, P., and Kumar, P. P. (2016). Plant hormone-mediated regulation of stress responses. BMC Plant Biol. 16, 1-10. doi: 10.1186/s12870016-0771-y

Wang, C., Zhao, Y., Gu, P., Zou, F., Meng, L., Song, W., et al. (2018). Auxin is involved in lateral root formation induced by drought stress in tobacco seedlings. J. Plant Growth Regulat. 37, 539-549. doi: 10.1111/ppl. 12444

Werner, T., Nehnevajova, E., Köllmer, I., Novák, O., Strnad, M., Krämer, U., et al. (2010). Root-specific reduction of cytokinin causes enhanced root growth, drought tolerance, and leaf mineral enrichment in Arabidopsis and tobacco. Plant Cell 22, 3905-3920. doi: 10.1105/tpc.109.072694

Wu, J., Kim, S. G., Kang, K. Y., Kim, J.-G., Park, S.-R., Gupta, R., et al. (2016). Overexpression of a pathogenesis-related protein 10 enhances biotic and abiotic stress tolerance in rice. Plant Pathol. J. 32:552.

Xue, L. J., Guo, W., Yuan, Y., Anino, E. O., Nyamdari, B., Wilson, M. C., et al. (2013). Constitutively elevated salicylic acid levels alter photosynthesis and oxidative state but not growth in transgenic populus. Plant Cell 25, 2714-2730. doi: $10.1105 /$ tpc.113.112839
Ye, H., Liu, S., Tang, B., Chen, J., Xie, Z., Nolan, T. M., et al. (2017). RD26 mediates crosstalk between drought and brassinosteroid signalling pathways. Nat. Commun. 8:14573. doi: 10.1038/ncomms 14573

Yu, L., Chen, X., Wang, Z., Wang, S., Wang, Y., Zhu, Q., et al. (2013). Arabidopsis enhanced drought tolerance1/HOMEODOMAIN GLABROUS11 confers drought tolerance in transgenic rice without yield penalty. Plant Physiol. 162, 1378-1391. doi: 10.1104/pp.113.217596

Yu, L. H., Wu, S. J., Peng, Y. S., Liu, R. N., Chen, X., Zhao, P., et al. (2016). Arabidopsis EDT 1/HDG 11 improves drought and salt tolerance in cotton and poplar and increases cotton yield in the field. Plant Biotechnol. J. 14, 72-84. doi: $10.1111 /$ pbi. 12358

Zahid, K. R., Ali, F., Shah, F., Younas, M., Shah, T., Shahwar, D., et al. (2016). Response and tolerance mechanism of cotton Gossypium hirsutum L. to elevated temperature stress: a review. Front. Plant Sci. 7:937. doi: 10.3389/fpls. 2016.00937

Zandalinas, S. I., Rivero, R. M., Martínez, V., Gómez-Cadenas, A., and Arbona, V. (2016). Tolerance of citrus plants to the combination of high temperatures and drought is associated to the increase in transpiration modulated by a reduction in abscisic acid levels. BMC Plant Biol. 16, 1-16. doi: 10.1186/s12870-0160791-7

Zhang, Y., Li, Y., Hassan, M. J., Li, Z., and Peng, Y. (2020). Indole-3-acetic acid improves drought tolerance of white clover via activating auxin, abscisic acid and jasmonic acid related genes and inhibiting senescence genes. BMC Plant Biol. 20, 1-12. doi: 10.1186/s12870-020-02354-y

Zhao, J., Yu, N., Ju, M., Fan, B., Zhang, Y., Zhu, E., et al. (2019). ABC transporter OsABCG18 controls the shootward transport of cytokinins and grain yield in rice. J. Exp. Bot. 70, 6277-6291. doi: 10.1093/jxb/erz382

Zwack, P. J., and Rashotte, A. M. (2015). Interactions between cytokinin signalling and abiotic stress responses. J. Exp. Bot. 66, 4863-4871. doi: 10.1093/jxb/erv172

Conflict of Interest: The authors declare that the research was conducted in the absence of any commercial or financial relationships that could be construed as a potential conflict of interest.

Publisher's Note: All claims expressed in this article are solely those of the authors and do not necessarily represent those of their affiliated organizations, or those of the publisher, the editors and the reviewers. Any product that may be evaluated in this article, or claim that may be made by its manufacturer, is not guaranteed or endorsed by the publisher.

Copyright (C) 2022 Iqbal, Wang, Mubeen, Kamran, Kanwal, Díaz, Abbas, Parveen, Atiq, Alshaya, Zin El-Abedin and Fahad. This is an open-access article distributed under the terms of the Creative Commons Attribution License (CC BY). The use, distribution or reproduction in other forums is permitted, provided the original author(s) and the copyright owner(s) are credited and that the original publication in this journal is cited, in accordance with accepted academic practice. No use, distribution or reproduction is permitted which does not comply with these terms. 